\title{
DESAIN AKUISISI SEISMIK LAUT 3D UNTUK EKSPLORASI HIDROKARBON DENGAN MENGGUNAKAN METODE ENHANCED STATIC
}

\author{
Bagus Wibisono, Widya Utama, dan Firman Syaifuddin
}

Departemen Teknik Geofisika, Fakultas Teknik Sipil Lingkungan dan Kebumian, Institut Teknologi Sepuluh Nopember (ITS)

e-mail: bagusws111@gmail.com

\begin{abstract}
Abstrak. Wilayah Madura Timur bagian utara terletak pada Cekungan Jawa Timur bagian utara yang didominasi oleh lingkungan karbonat. Pada lingkungan karbonat gelombang seismik yang merambat mengalami pelemahan sehingga menghasilkan data dengan rasio $\mathrm{S} / \mathrm{N}$ yang rendah. Dalam akuisisi data seismik penentuan desain akuisisi menentukan kualitas data yang didapatkan, penentuan parameter yang tidak tepat dan sesuai dengan target akan menghasilkan penampang seismik dengan rasio $\mathrm{S} / \mathrm{N}$ yang rendah sehingga tidak mampu menunjukan perlapisan bawah permukaan. Lapisan target pada penelitian ini merupakan lapisan basement pada kedalaman $4237 \mathrm{~m}$. Proses penentuan parameter desain akuisisi dilakukan dengan metode statik dan enhanced static dengan analisa kuantitatif yang kemudian disimulasikan pada model geologi sintetik tanpa menggunakan atenuasi gelombang untuk di analisa secara kualitatif. Parameter desain 2D enhanced static yang didapatkan yaitu fold coverage 45, interval CDP $11 \mathrm{~m}$ dan offset $4000 \mathrm{~m}$ dengan konfigurasi off end yang kemudian diaplikasikan pada desain akuisisi seismik 3D. Parameter desain akuisisi seismik 3D yang dianalisa adalah interval jumlah streamer, dan offset. Desain akuisisi 3D yang didapatkan antara lain konfigurasi offend dengan 6 buah streamer dengan interval $21.5 \mathrm{~m}$ dan tiap streamer memiliki 187 buah receiver dengan interval $21.5 \mathrm{~m}$. Jumlah source tiap lintasan adalah 551 buah dengan interval 43m dengan jumlah lintasan 196 buah untuk lintasan receiver dan source dengan interval $64.5 \mathrm{~m}$. Jumlah fold yang didapat adalah 45 dan offset $4000 \mathrm{~m}$. Berdasarkan hasil analisa, metode enhanced static mampu menunjukan reflektor lebih jelas. Untuk meningkatkan akurasi hasil desain akuisisi, analisa dengan menggunakan atenuasi gelombang, analisa berdasarkan model geologi 3D dan dari sisi ekonomis dapat dilakukan.
\end{abstract}

Kata Kunci: Desain Akuisisi Seismik 3D; Fold Coverage; Offset; Perambatan Gelombang; Streamer

\begin{abstract}
The Northern Eastern Madura region lies in the northern part of the East Java Basin which is dominated by the carbonate environment. In carbonate environments, seismic wave that propagate are weaken so that generate data with a low $S / N$ ratio. In seismic data acquisition, the determination of the acquisition design will influence the quality of the data obtained. Improper parameter determination will produce a seismic section with a low $S$ / $N$ ratio so that it is unable to show subsurface layers. The target layer on this research is the basement layer at $4237 \mathrm{~m}$ depth. The process of determining the acquisition design parameters is performed by static and enhanced static method with quantitative analysis which then simulated on synthetic geological model without using wave attenuation for qualitative analysis. 2D enhanced static design parameters are (1) fold coverage 45, (2) CDP interval $11 \mathrm{~m}$ and (3) offset 4000m with off-end configuration which was then applied to 3D seismic acquisition design. The analyzed 3D seismic acquisition design parameters were interval number of streamer, and offset. 3D acquisition designs include an off-end configuration with 8 streamers with $21.5 \mathrm{~m}$ intervals and each streamer has 187 receivers with intervals of $21.5 \mathrm{~m}$. The number of sources per track is 551 pieces at $43 \mathrm{~m}$ intervals with a total of 196 passes for the receiver and source paths at 86m intervals. The number of fold is 45 and offset $4000 \mathrm{~m}$. Based on the analysis, the enhanced static method is able to show the reflector more clearly. To improve the accuracy of the acquisition design results, the analysis by using wave attenuation, analysis based on 3D geological model and from the economic side can be performed.
\end{abstract}

Keywords: 3D Seismic Design Acquisition; Fold Coverage; Offset; Wave Propagation; Streamer 


\section{PENDAHULUAN}

Cekungan Jawa Timur bagian Utara merupakan jenis cekungan lingkungan karbonat dan termasuk cekungan belakang busur yang berada pada batas tenggara dari Lempeng Eurasia. Pada lokasi ini sebelumnya sudah dilakukan akuisisi data seimik 2D yang mana menunjukan adanya prospek minyak bumi. Berdasarkan hasil akuisisi seismik 2D tersebut maka dapat dikembangkan eksplorasi dengan menggunakan seismik 3D. Pada lingkungan karbonat, gelombang seismik yang merambat mengalami pelemahan sehingga menghasilkan data seismik dengan rasio $\mathrm{S} / \mathrm{N}$ yang rendah. Rasio $\mathrm{S} / \mathrm{N}$ yang rendah tersebut disebabkan karena adanya kontras kecepatan dan densitas yang tinggi. Nilai kontras yang tinggi menyebabkan gelombang seismik cenderung dipantulkan sehingga kenampakan reflektor dibawah lapisan karbonan menjadi tidak jelas.

Penelitian ini dilakukan untuk mendapatkan desain akuisisi seismik 3D berdasarkan data sesimik 2D yang sudah tersedia. Dalam penentuan desain akuisisi tersebut digunakan metode enhanced static untuk mendapatkan data seismik dengan signal to noise ratio $(\mathrm{S} / \mathrm{N})$ yang tinggi sehingga mampu menunjukan lapisan target dengan baik. Lapisan target pada penelitian ini merupakan lapisan basement yang berada dibawah lapisan karbonat. Penelitian ini juga bertujuan untuk mendapatkan parameter desain akuisisi 3D dan membandingkan metode desain akuisisi statik dengan metode enhanced static. Parameter desain akuisisi yang dianalisa pada penelitian ini adalah interval common depth point (CDP), fold coverage, far offset, dan jumlah streamer.

\section{Geologi Regional}

Daerah penelitian terletak pada sebelah Timur Pulau Madura yang terletak pada lepas pantai Pulau Madura. Daerah tersebut termasuk pada Cekungan Jawa Timur bagian Utara yang dikelompokkan sebagai cekungan belakang busur yang terbentuk akibat tumbukan Lempeng Hindia Australia yang bergerak kearah utara terhadap lempeng Sunda yang dicirikan oleh anomali rendah didaerah tumbukan dan anomali tinggi didaerah pegunungan selatan Jawa (Fatahillah dkk., 2016). Kerangka tektonik cekungan Jawa Timur Utara berupa graben, half-graben dan sesar-sesar hasil dari proses rifting yang dihasilkan pada periode ekstensional yaitu pada masa Paleogen (Panjaitan, 2010).
Pada Zaman Kapur Akhir cekungan ini merupakan cekungan laut di bagian selatan zona subduksi (Satyana dan Purwaningsih, 2003). Cekungan Laut Jawa Bagian Timur dibatasi di bagian barat oleh Busur Karimunjawa, di bagian timur oleh laut dalam Lombok, Flores, Salayar dan Cekungan Makasar Selatan. Cekungan ini memanjang ke arah timur-laut dari lepas pantai busur volkanik Laut Jawa hingga ujung tenggara Kalimantan dan bergabung dengan bagian selatan Selat Makasar dan dibatasi dibagian timur-laut oleh Paternoster Platform dan Zona Sesar Adang (Satyana dan Purwaningsih, 2003).

\section{Interval Common Depth Point (CDP) dan Ukuran Bin}

Ketika sumber gelombang diberikan dibawah permukaan, maka gelombang tersebut akan memantul ketika bertemu dengan medium yang berbeda. Pada seimsik 2D jarak antar titik pantul tersebut merupakan CDP interval. Sedangkan pada seismik 3D, titik pantul tersebut berada pada suatu bidang atau area yang disebut BIN. CDP merupakan banyaknya gelombang yang melalui titik atau target yang sama. Sehingga ketika semakin banyak CDP pada satu titik maka data yang didapatkan akan memiliki rasio $\mathrm{S} / \mathrm{N}$ yang tinggi. (Chaouch dan Mari, 2006). Untuk mendapatkan interval CDP atau ukuran BIN tersebut digunakan persamaan (1) berikut:

$\mathrm{CDP} /$ Ukuran $B I N=\frac{V r m s}{4 \times f \max x \tan \alpha}$

dengan Vrms adalah kecepatan rata - rata lapisan, fmax adalah frekuensi maksimal dari gelombang seismik, dan $\tan \alpha$ adalah nilai tan dari sudut kemiringan maksimum target (Chaouch dan Mari, 2006).

\section{Far Offset}

Far offset merupakan jarak terjauh antara sumber gelombang dengan receiver yang dapat merekam sumber gelombang tersebut. Far offset akan mempengaruhi kedalaman yang didapatkan pada akuisisi data seismik seperti pada persamaan berikut ini :

$\mathrm{H}(\max )=0.5 \times \mathrm{Z} \times\left(\left(\frac{V+V s}{V-V S}\right)^{\frac{1}{2}}\right.$

dimana $\mathrm{H}$ (max) adalah far offset, $\mathrm{Z}$ adalah kedalaman target, $\mathrm{V}$ adalah kecepatan rata - rata hingga lapisan target, dan Vs adalah kecepatan pada lapisan permukaan (Talagapu, 2005).

\section{Jumlah Channel}


Penentuan jumlah receiver ditentukan berdasarkan panjang lintasan serta jarak antar receiver. Penentuan jumlah receiver ini akan mempengaruhi fold coverage yang didapatkan ketika akuisisi. Namun, nilai fold coverage tidak hanya ditentukan oleh receiver, melainkan dipengaruhi juga oleh source. Adapun untuk menghitung jumlah receiver dapat menggunakan persamaan sebagai berikut ini:

$\sum C h=\frac{\text { Far offset }}{\Delta R}$

dimana $\Sigma C h$ merupakan jumlah dari receiver dalam satu lintasan, $\Delta R$ merupakan jarak atau interval antar receiver. Persamaan teresbut digunakan acuan untuk menentukan jumlah receiver yang digunakan (Cordsen dkk., 2000).

\section{Desain Akuisisi Seismik Laut}

Akuisisi data seismik laut dilakukan dengan menggunakan beberapa streamer terletak yangdi belakang kapal. Setiap streamer menggabungkan ratusan hidrophon yang diletakan pada jarak tertentu. Panjang satu streamer dapat mencapai 6 sampai 8 kilometer. Pada bagian belakang kapan terdapat satu atau lebih sumber seismik. Sumber seismik tersebut biasanya berasal dari rangkaian airguns(Biondi, 2006). Untuk melakukan akuisisi, seperti pada halnya seismik darat perlu dibuat terlebih dahulu desain akuisisinya. Tujuan utama dari pembuatan desain akuisisi adalah untuk mendapatkan sampel kubus yang cukup yang dapat menggambarkan secara akurat dari hasil migrasi poststack. Parameter desain lainnya yang juga penting adalah offset. Offset minimum harus sekecil mungkin agar dapat cukup mencangkup target dangkal. Offset maksimum harus sebesar mungkin agar mendapatkan estimasi kecepatan yang akurat yang dibutuhkan untuk penggambaran stacking dan poststack (Biondi, 2006).

\section{METODOLOGI}

Penelitian dilakukan untuk mendapatkan desain akuisisi sesimik 3D dengan menggunakan metode enhanced static dan membandingkan metode tersebut dengan metode statik. Data yang digunakan dalam penelitian ini adalah 25 buah lintasan seismik 2D dan 1 buah data sumur. Data sumur yang digunakan adalah well marker, log densitas, dan log sonik. Lokasi penelitian berada disebelah Timur pulau Madura dengan luas area penelitian sebesar $396,6 \mathrm{~km}^{2}$.
Berikut ini merupakan diagram alir dari penelitian yang dilakukan :

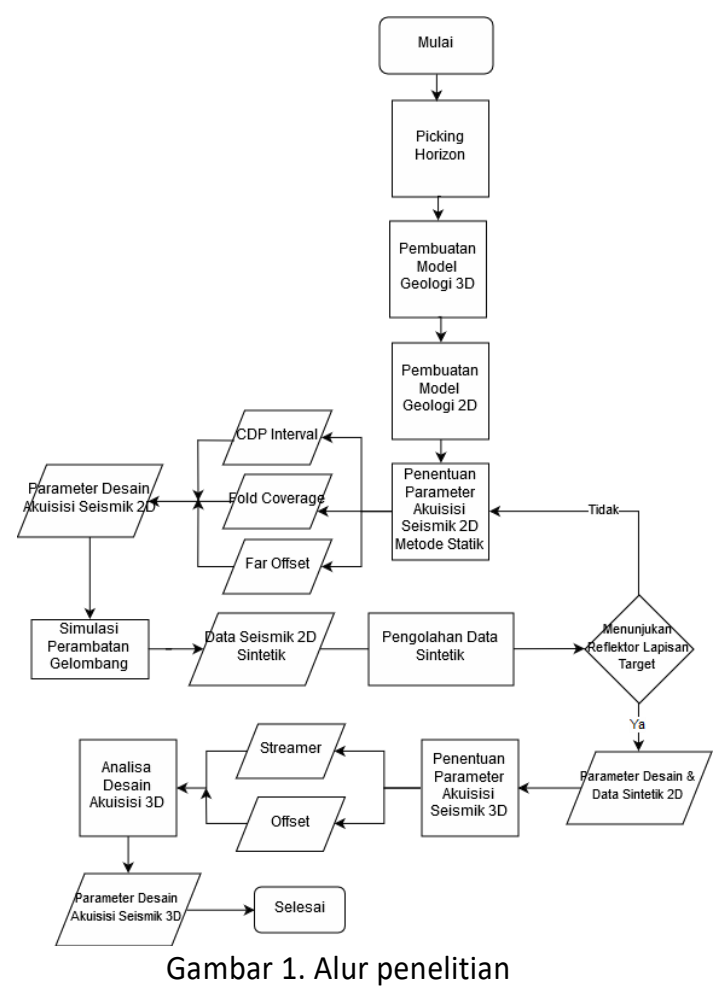

Penelitian ini terbagi menjadi 2 tahap, yaitu tahap pembuatan model dan pembuatan desain akuisisi. Model geologi sintetikini dibuat berdasarkan data seismik serta data sumur yang ada. Model tersebut akan dibutuhkan untuksimulasi desain akuisisi yang dibuat. Setelah membuat model geologi sintetik, selanjutnya adalah menentukan parameter desain akuisisi berdasarkan analisa kuantitatif berdasarkan persamaan yang ada. Analisa secara kuantitatif ini disebut juga metode statik. Setelah didapatkan parameter desain berdasarkan analisa kuantitatif, maka akan dilakukan simulasi desain akuisisi pada model geologi sintetik yang telah dibuat. Simulasi tersebut akan menghasilkan data seismik sintetik yang akan dianalisa kualitasnya secara kualitatif.

\section{HASIL DAN PEMBAHASAN}

Pada tahap pembuatan model geologi terdapat beberapa langkah yang harus dikerjakan, yaitu pengikatan data sumur dengan data seismik, ekstrapolasi data sumur dan picking horizon untuk menentukan batas lapisan. Informasi parameter lapisan bawah permukaan berupa nilai densitas dan 
kecepatan lapisan juga didapatkan dari data sumur tersebut. Pada tahap pembuatan tersebut menghasilkan informasi jumlah lapisan bawah permukaan dengan nilai densitas dan kecepatan seperti pada tabel 1 berikut.

Tabel 1. Jumlah Lapisan serta Parameter Fisis Lapisan

\begin{tabular}{ccccc}
\hline Sumur & Lapisan & $\begin{array}{c}\text { Kedalaman } \\
(\mathbf{m})\end{array}$ & $\begin{array}{c}\text { Kecepatan } \\
\text { Interval(m/s) }\end{array}$ & $\begin{array}{c}\text { Densitan } \\
\left(\mathbf{k g} / \mathbf{m}^{3}\right)\end{array}$ \\
\hline PJG-1 & Water & $0-258$ & 1500 & 1000 \\
PJG-1 & Seafloor & $258-376$ & 1139.936276 & 1780.057 \\
PJG1 & EJ8-TbNCarb & $376-556$ & 1344.537143 & 1886.59 \\
PJG-1 & EJ1-A & $556-847$ & 1732.407394 & 2043.906 \\
PJG-1 & EJ1-B & $847-941$ & 1593.597778 & 2135.427 \\
PJG-1 & EJ1-C & $941-2887$ & 2717.037763 & 2404.456 \\
PJG-1 & EJ5-CDCarb & $2887-3248$ & 4486.109628 & 2697.393 \\
PJG-1 & EJ4-NGBCarbShale & $3248-3368$ & 4620.142719 & 2662.986 \\
PJG-1 & EJ4-NGBClastic & $3368-3646$ & 4649.858514 & 2661.14 \\
PJG-1 & EJ3-SynRift-2 & $3646-3958$ & 5130.443309 & 2804.559 \\
PJG-1 & EJ2-SynRift-1 & $3958-4237$ & 5690.108443 & 2821.649 \\
PJG-1 & Basement & $>4237$ & 6549.725531 & 2810.164 \\
\hline
\end{tabular}

Informasi kedalaman lapisan target; yang pada penelitian ini merupakan lapisan basement; dibutuhkan untuk menentukan nilai far offset dalam analisa kuantitatif. Kemudian kecepatan interval dan densitas lapisan akan mempengaruhi perambatan gelombang dalam simulasi desain akuisisi berdasarkan analisa kuantitatif. Berdasarkan informasi kecepatan interval pada tabel 1. lapisan yang merupakan batuan karbonat berada pada kedalaman $2887 \mathrm{~m}$. Hal tersebut karena terdapat kontras kecepatan yang sangat tinggi. Kontras kecepatan yang sangat tinggi tersebut akan mempengaruhi perambatan gelombang seismik karena gelombang tersebut akan cenderung dipantukan sehingga lapisan yang berada dibawahnya tidak tercitrakan dengan baik.

Setelah pembuatan model geologi, maka selanjutnya adalah menentukan paramter desain akuisisi seismik 2D berdasarkan analisa kuantitatif. Anaisa kuantitatif dilakukan dengan menghitung nilai interval CDP, kemudian nilai fold coverage, dan nilai far offset. Berdasarkan analisa kuantitatif tersebut didapatkan parameter desain akuisisi seperti pada tabel 2 .

Tabel 2. Parameter Desain Akuisisi Analisa Kuantitatif

\begin{tabular}{ll}
\hline Parameter & Ukuran \\
\hline CDP Interval & $22 \mathrm{~m}$ \\
Jumlah Shot & 551 \\
Jumlah Receiver & 93 \\
Interval Shot & $43 \mathrm{~m}$ \\
Interval Receiver & $43 \mathrm{~m}$ \\
Far Offset & 3193.517 \\
& $\mathrm{~m}$ \\
Fold & 45 \\
\hline
\end{tabular}

Parameter tersebut kemudian disimulasikan untuk mengetahui data seismik yang didapatkan. Data seismik yang didapatkan dianalisa secara kualitatif untuk mengetahui bahwa lapisan target sudah tercitrakan dengan baik atau belum. Analisa tersebut dilakukan berdasarkan parameter interval CDP, fold coverage, dan far offset. Setelah dianalisa, lapisan target bedasarkan desain akuisisi tersebut belum mampu mencitrakan lapisan target dengan jelas karena terdapat kemenerusan yang tidak menerus sehingga dilakukan penentuan desain akuisisi kembali untuk meningkatkan kualitas data. Gambar 2. merupakan data hasil desain akuisisi berdasarkan analisa kuantitatif dan gambar 3 . merupakan data hasil desain akuisisi berdasarkan analisa kualitatif. 


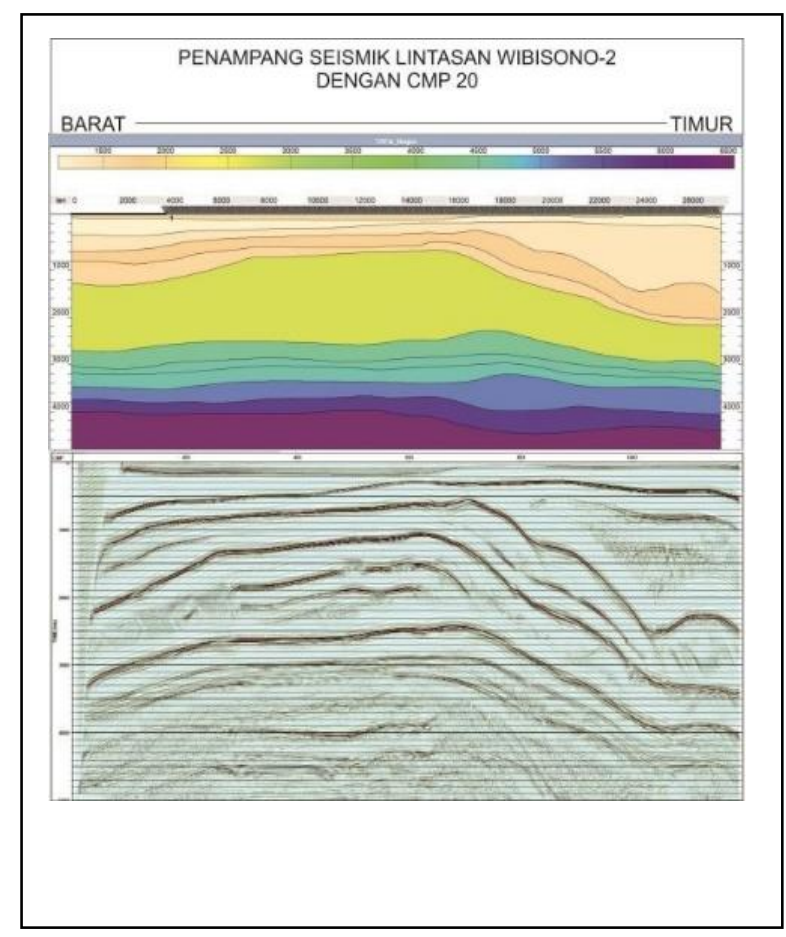

Gambar 2. Desain akuisisi analisa kuantitatif

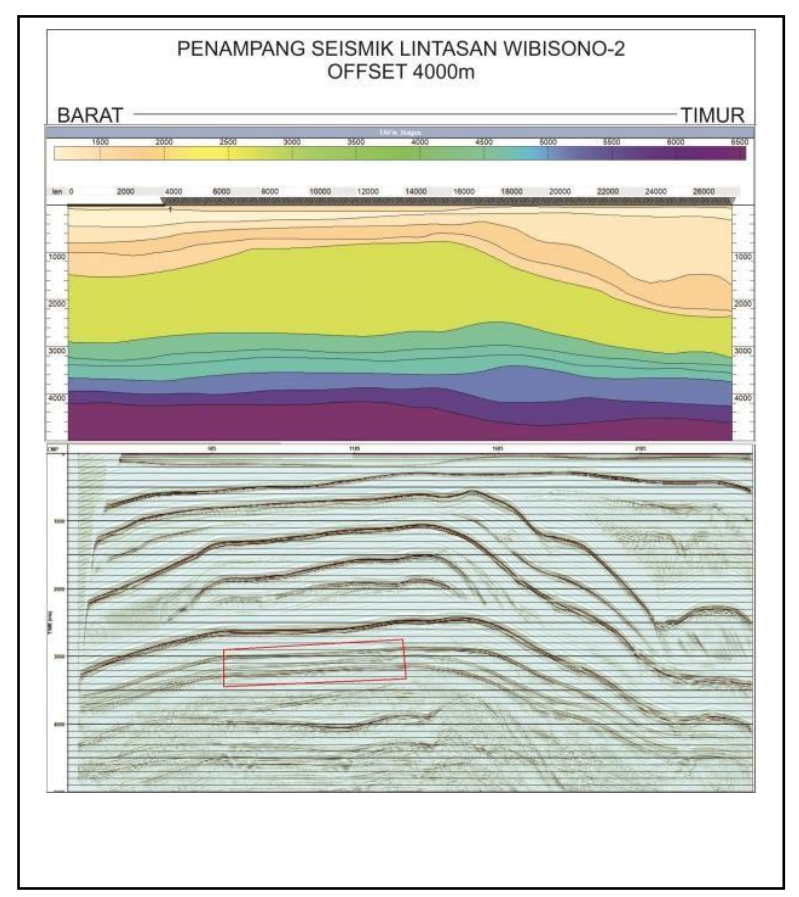

Gambar 3. Desain akuisisi analisa kualitatif

Berdasarkan kedia gambar tersebut, dapat dilihat bahwa kemenerusan pada gambar 3 terlihat lebih jelas terutama pada lapisan. Penentuan desain akuisisi pada gambar 3. dilakukan berdasarkan analisa parameter desain, yaitu interval CDP, fold coverage, dan far offset dengan beberapa variasi parameter sebagai pembanding. Hasil desain akuisisi dengan analisakualitatif terdapat pada tabel3.
Tabel 3. Parameter Desain Akuisisi Analisa Kuantitatif

\begin{tabular}{ll}
\hline Parameter & Ukuran \\
\hline CDP Interval & $11 \mathrm{~m}$ \\
Jumlah Shot & 551 \\
Jumlah Receiver & 187 \\
Interval Shot & $43 \mathrm{~m}$ \\
Interval Receiver & $21,5 \mathrm{~m}$ \\
Far Offset & $4000 \mathrm{~m}$ \\
Fold & 45 \\
\hline
\end{tabular}

Parameter desain akuisisi hasil analisa kuantitatif tersebut akan dijadikan sebagai acuan dalam penentuan desain akuisisi seismik 3D. Penentuan desain akuisisi seismik 3D dilakukan dengan menganalisa parameter jumlah streamer dan offset. Pada penelitian ini terdapat 3 buah variasi nilai parameter pada masing-masing parameter. Pada jumlah streamer penulis membandingkan 4,6 dan 8 buah streamer. Berdasarkan analisa pada ketiga parameter tersebut, penggunakan 6 buah streamer menghasilkan persebaran trace yang lebih merata pada keseluruhan offset sehingga penulis menggunakan parameter 6 buah stramer.

Setelah menentukan jumlah streamer penulis membandingkan jarak offset yang digunakan. Nilai parameter yang digunakan adalah $4000 \mathrm{~m}, 3000 \mathrm{~m}$, dan 2000m. Berdasarkan analisa tersebut jumlah fold terbanyak dengan persebaran yang baik terdapat pada offset $4000 \mathrm{~m}$ sehingga penulis menguunakan parameter tersebut. Maka berdasarkan analisa tersebut penulis mendapatkan parameter desain akuisisi3D seperti pada tabel 4 .

Tabel 4. Parameter Desain Akuisisi 3D

\begin{tabular}{ll} 
Parameter & Ukuran \\
\hline Konfigurasi & Off End \\
Jumlah Streamer & 6 \\
Interval Streamer & $21.5 \mathrm{~m}$ \\
Interval CDP & $11 \mathrm{~m}$ \\
Jumlah Shot/lintasan & $551 \mathrm{buah}$ \\
JumlahReceiver/Streamer & $187 \mathrm{buah}$ \\
Interval Shot & $43 \mathrm{~m}$ \\
Interval Receiver & $21.5 \mathrm{~m}$ \\
Jumlah Receiver Line & $260 \mathrm{buah}$ \\
Jumlah Shot Line & $260 \mathrm{buah}$ \\
Interval Receiver Line & $64.5 \mathrm{~m}$ \\
Interval Shot Line & $64.5 \mathrm{~m}$ \\
Far Offset & $4000 \mathrm{~m}$ \\
Fold Coverage & 45 \\
\hline
\end{tabular}




\section{PENUTUP}

\section{Simpulan dan Saran}

Hasil desain akuisisi dengan menggunakan enhanced static lebih baik dibandingkan dengan menggunakan metode statik. Hal tersebut karena desain akuisisi enhanced static menghasilkan penampang seismik yang lebih baik karena menunjukan kemenerusan reflektor yang lebih jelas sehingga parameter desain akuisisi metode enhanced static dapat dijadikan rekomendasi.

Berdasarkan penelitian yang telah dilakukan, penulis menyarankan untuk menggunakan atenuasi gelombang agar data yang dihasilkan lebih mendekati kondisi alam sehingga data yang didapatkan lebih akurat. Kemudian, penulis menyarankan untuk dilakukan analisa lebih lanjut dengan menggunakan metode Full Wave Form pada desain akuisisi 3D serta analisa dari segi ekonomis.

\section{DAFTAR PUSTAKA}

Biondi, B. (2006), 3D Seismic Imaging, Investigations in Geophysics, Society of Exploration Geophysicists. http://doi.org/10.1190/1.9781560801689.

Chaouch, A. dan Mari, J.L. (2006), "3-D Land Seismic Surveys: Definition of Geophysical Parameter", Oil \& Gas Science and Technology - Revue de I'IFP, Vol.61, No.5, hal. 611-630. http://doi.org/10.2516/ogst:2006002.

Cordsen, A., Galbraith, M. dan Peirce, J. (2000), Planning Land 3-D Seismic Surveys, Geophysical Developments Series, Society of Exploration Geophysicists. http://doi.org/10.1190/1.9781560801801.

Fatahillah, Y., Hilyah, A. dan Utama, W. (2016), "Penentuan Potensi Batuan Induk Menggunakan Model Log Toc Pada Formasi Ngimbang, Lapangan "Arrazi", Cekungan Jawa Timur Utara", Jurnal Teknik ITS, Vol.5, No.2, hal. B352-B354-B354. http://doi.org/10.12962/j23373539.v5i2.18240

Panjaitan, S. (2010), "Prospek Migas pada Cekungan Jawa Timur dengan Pengamatan Metode Gaya Berat", Buletin Sumber Daya Geologi, Vol.5, No., hal. 168-181

Satyana, A.H. and M. E. M. Purwaningsih, "OligoMiocene carbonates of Java: Tectonic Setting and Effects of Volcanism," in Proceedings of Joint Convention Jakarta 2003 . The 32nd IAGI and 28th HAGI Annual Convention and Exhibition, 2003, no. 1, hal. 1-27.

Talagapu, K.K. 2005. 2D and 3D Land Seismic Data
Acquisition and Seismic Data Processing. Department of Geophysics, College of Science and Technology Andhra University. Andhra Pradesh. 